well seen, for we all regard $\mathrm{Mr}$. Booth as one of the very loss of power in the left shoulder. On the 5th the joints in ablest and very best students at Guy's, but perhaps the both legs became painful and swollen, so a doctor was sent main fact was that all were quite sure that there was only one bacterium. Next lecture we will take up in detail the consideration of the history of contagion.

\title{
A CASE OF ULCERATIVE ENDOCARDITIS WITH PYAMIC SYMPTOMS.
}

\section{BY JULIUS POLLOCK, M.D.,} rhysictan to Charing-Cross hospital.

Atrention has Jately been drawn by Dr. Sidney Coupland, Dr. Wilks, and others, to a rare and interesting form of ulcerative endocarditis with pyamic symptoms. In most, if not all, of the cases there has been old valvular mischief of the heart, upon which the fresh ulceration has been grafted, and some importance has been attached to the presence of former cardiac mischief. In the following case the symptoms came on during the course of a first attack of rheumatic fever, the heart being quite sound; and it has this further interest, that the case is absolutely complete, having been under observation from the first appearance of the rheumatic fever until the closing scene. I am indebted to Mr. C. A. Wigan, resident medical officer, for the care. fully prepared notes of the case.

M. J_ aged twenty-two, a single woman, was admitted into Charing-cross Hospital, under the care of Dr. Pollock, on Sept. 7th, 1882, suffering from a first attack of acute rheumatism. On admission she complained of pain in both knees and ankles and in the shoulder of the left arm. She also had some pain and stiffoess in the joints of the right hand. Temperature $1012^{\circ}$; pulse 84 ; heart normal, with no irregufor, who recommended her to go into a hospital, and accorl.
ingly she was admitted into Charing-cross Hospital on Sept. 7 th.

Her temperature on admission was $1012^{\circ}$, and the pulse 84 . There was the usual sour-smelling sweat, and the urine was high-coloured and acid, but otherwise normal. The heart was carefully examined, and found to be normal As the bowels were contined, she was ordered ten grains of colocynth and calomel pill for that night, and the following mixture: Salicylate of soda, fifreen grains; carbonate of ammonia, four grains; decoction of ciuchona, one ounce, every six hours. A chart of the temperature, taken every four hours, was started.--Sept. 3rd : No change in temperature. The urine contained no albumen, but was found to be very acid, and thirty grains of bicarbonate of potash and three grains of iodide of potash were added to the mixture. Pills repeated. The patient shortly lost all pain in the right arm, both knees, and ankles, but suffered much in her left shoulder and arm, the slightest movement causing great pan. Pulse about 90 ; heart normal.28th : Patient still complains of great pain in the left arm, especially in the muscles of the upper part. The temperature at 6 P.M. was $102 \cdot 8^{\circ}$, consequent'y the old mixture was discontinued, and the following ordered:Sulphate of quinine, two grains; carbonate of ammonia, two grains; bicarbonate of potash, twenty grains; chlo. roform water, two drachms; to one ounce of water: to be taken three times a day. This seemed to have a very beneficial effect, as the temperature fell to normal, and remained so until the morning of October 2nd, when at 9 A. M., without any apparent cause, she was seized with a severe rigor, lasting fifteen minutes, and followed by a profuse sweat. The temperature ran up from $98^{\circ}$ to $102^{\circ} 4^{\circ}$, but fell at 2 P. M. to $100 \cdot 6^{\circ}$; rising again to $1026^{\circ}$ at 6 P. P. $_{0}$ 3rd: The temperature at 2 P.Mr. was $98^{\circ}$, bus another rigor, as severe as before, occurred at 12 P.M., the temperature

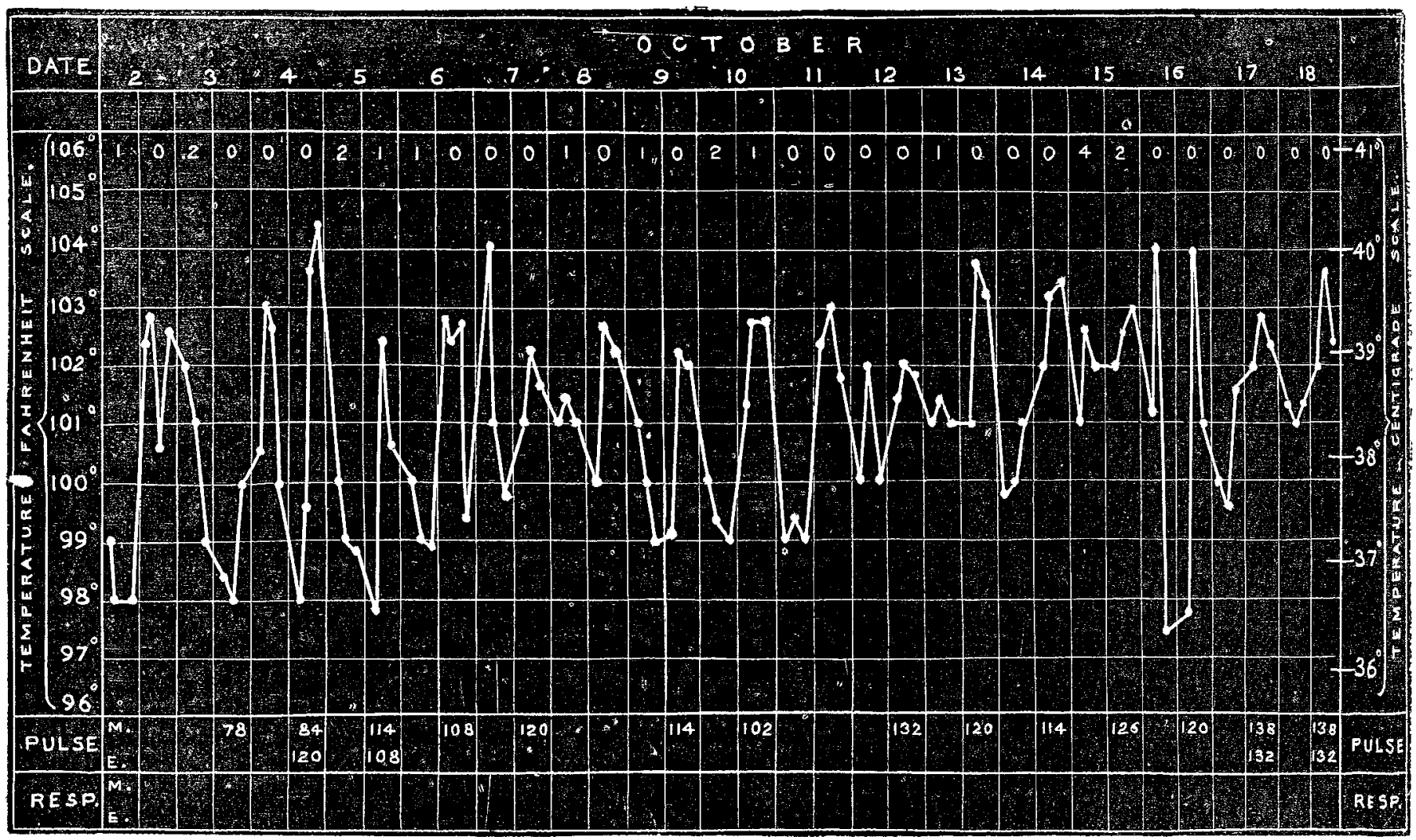

larity nor bruit. From her previous history she appears to rising to $103^{\circ}$. -4 th: Another rigor at 6 P.1I, tempecature have had measles when an infant, but no other serious complaint. Her father died of pleurisy (double) aged fortyfour ; had always been a healthy man. Her mother is still alive and healthy. Three brothers and five sisters alive and healthy; four died quite yourg. The patient states that on Sept. 3rd, the day before she felt jll, she had a hot bath and went out for a walk directly afterwards in the rain, and got wet through. The same night she felt chilly and sick, and vomited shortly after getting into bed a greenish fluid with a bitter taste. Patient got no rest during the night, owing to the feeling of sickness, which continued. The next day (Sept. 4th) she got up. She did not complain of any chilliness or fever, but felt some stiffness and experienced $1044^{\circ}$. -6th: Another rigor at 9 A. II. ; temperature 102: The rigors were followed by a profuse sweat in a quarter of an hour. Up to this date the heart-sounds had been normal, avd excepting some increase at the tine of the rigors, the pulse-rate had varied from 76 to 96 per ininute: but on the morning of the 6 th a very soft and indis:iver whiff was heard with the first sound at the apex of the heart. This gradually developed, until, on the morning of the 12th, a characteristic murmur was plainly heard at the apt.: with the first sound, and was gradually lost when tracet? into the axilla.--14th: Three grains of the sulphate of quinine were given in milk three times a day, and four oudes of brandy per diem. -16 th : The murmur is now rerg lis. 
tinct, and is rasping in character. It can be heard all over the chest. A very wide range of temperature was noted to-day- $104^{\circ}$ at 2 A.M., $97^{\circ}$ at 6 A.M., $104^{\circ}$ at 2 P.M., and $101^{\circ}$ at 6 P.M. -17 th : Up to this date the breathing has been fairly good, and not much increased in rate; but to-day she has had a short and irritating cough. Respiratory murmur harsh, no dulness on percussion, slight amount of sputum. The pulse was quickened considerably, being 138 in the morning and 132 in the evening. - 18th: The variations in temperature are not so severe; it now ranges between $101^{\circ}$ and $103^{\circ}$; pulse still 138 . Cough harder, sputa more abundant, and rather rusty. Respiratory murmur harsher; dyspnea at times. She complains of loss of appetite and a feeling of sickness, and has not slept for two nights. Ordered solution of hydrochlorate of morphia, five minims ; nitrate of bismuth, ten grains; bicarbonate of soda, ten grains; compound tragacanth powder, ten grains; to one ounce of water: to be taken at bedtime. This had a good effect, and she slept for five hours. - 19th: Dyspnoea has a good deal increased. The cough is irritable; sputum very rusty, almost red, but with a greenish-purple tint here and there. Some dulness and bronchial breathing over both bases. Pulse 138 in the morning and 150 in the evening. The cardiac bruit is very loud and harsh. Brandy increased to eight ounces. - 20th : Dyspncea very marked. Pulse 138. Dulness on percussion most distinct over the middle of the left lower lobe. Temperature $103 \cdot 6^{\circ}$. 2Ist: Breathing very laboured; respiration 56 . Very small crepitation over the left lower lobe; coarse râles over the right base. Temperature $101^{\circ}$; pulse 138 , very feeble, and evidently failing. Sputa free in quantity, of a dark-prune colour. Very small amount of urine passed; sp. gr. 1021, and a trace of albumen for the first time. $-22 n d$ : At $2 \mathrm{~A} \mathrm{M}$. the patient was comatose, the pulse being just perceptible. Death took place quietly two hours later.

Necropsy, thirty-four hours after death. - The body was well nourished; some rigor mortis still present, and no external appearances of disease. On opening the chest, the left side was found to be full of fluid ; there was also some, but less, in the right. The left lang was indurated about its middle third, and the upper part of the lower lobe was of a dark prune colour, with granular consolidation, and readily broken down. There were evidently two or three infarctions of recent date. The rest of the lung contained a small amount of serum, but was otherwise healthy. The right lung was the seat of four or five indurated patches, the result of pyæmic pneumonia, and also contained some serum. The heart weighed nine ounces and a half. The wall of the left ventricle was somewhat thickened, and there was recent ulceration on the right border of the mitral valve, and around it some exuberant vegetations, soft and easily detached. These were continuous for nearly an inch along the right border of the valve. No atheroma, no other valvular mischief. The liver was normal, weight fifty-one ounces. The spleen normal, weight eight ounces and a half. The kidneys weighed nine ounces and a half. Their capsules were slightly adherent, and the pvramids congested, otherwise healthy. Brain normal, weight forty ounces.

Remarks. - Ulcerative endocarditis with pyæmic symptoms must be very rare. I have watched with much interest the course of a large number of cases of acute rheumatism, many of which were accompanied by valvular cardiac disease, but the above case is the first of its kind that I have come across. What is it that determines the pyæmic symptoms? Presumably the presence in the blood of minute orgarisms-microzymes : but how they get there is as yet unexplained. As Dr. Burdon-Sanderson has pointed out, ${ }^{I}$ it is necessary for the production of infective disease that there should be present at the same time inflammation and bacteria; either may exist alone, but no pyæmic symptoms result. In the foregoing case the absence of all trace of metastatic abscesses in the liver, spleen, and kidneys is rather remarkable. The chief evidence of the existence of pyæmic dissemination was found in the lungs, and during life the sputa were very characteristic. The treatment of ulcerative endocarditis with pyæmia is most unsatisfactory. None of the ordinary remedies had any real effect, nor did large doses of alcohol sensibly improve matters. I wish now that I had tried the inhalation of carbolic acid, or the carbolate of iodine, and I would suggest giving such a line of treatment a fair trial in any cases of the kind, especially where the lungs appear to be much affected. Harley-street, $\mathrm{W}$.

1 Lumleian Lectures, 1882

\section{REMARKS UPON THE OSSEOUS LESIONS OF} LOCOMOTOR ATAXY,

\author{
WITH A CASE SIMULATING MALIGNAYT DISEASE.
}

By J. ALEX. WILLIAMS, M.B., M.R.C.S.,

HOUSE-SURGEON TO THE ROYAL PORTSMOUTH HOSPITAL, LATE HOUSEPHYSICIAN TO THE LONDON HOSPITAL.

The conspicuous absence from our museums, previous to the researches of Charcot, of specimens illustrating the osseous and articular lesions of locomotor ataxy, induced Sir James Paget ${ }^{1}$ daring the meeting of the late International Congress to ask Professor Charcot, "Whether these are not instances of a disease which has lately for the first time appeared, or at least has lately become much more frequent than formerly it was?" Now with all due deference to so great an authority, I cannot but think that their more frequent recognition in modern times is mainly owing to the increased facilities afforded us for the diagnosis of the disease in its early or pre-ataxic stage, and this is chiefly due to the labours of Duchenne, Westphal, Erb, Hutchinson, Jackson, Charcot, Buzzard, Robertson, and many others. For Professor $\mathrm{Erb}^{2}$ writes, "this arthropathy is most common in the early stages of tabes, and chiefly in the preliminary period betore the ataxic disturbances of motion have appeared, and when the lancinating pains constitute the chief feature of the complaint," and this assertion I believe holds good for the osseous lesions. Hence it is highly probable before the diagnostic significance of "lightning pains, "ocular paresis, and Westphal's symptom were known, that many cases presenting tabetic arthropathies, or osseous lesions, were diagnosed as examples of rheumatoid arthritis, or of malignant disease of bone, \&c., as might easily have been done in the case now recorded. The trequency with which patients describe their pains as "rheumatic" is strong presumption in favour of this view. Dr. Hughlings-Jackson, ${ }^{3}$ referring to a case of tabes whose only symptom besides lightning pains was the Argyll-Robertson pupil, says "the case might be taken for one of neuralgia only by those who have not studied lightning pains, and who do not examine the pupils." Dr. Buzzard in a foot-note to his paper ${ }^{4}$ upon the subject, says, referring to the arthropathies, "In most of those which I have published, the nature of the underlying disease had never been suspected." He instances a case in which excision of the knee-joint was very nearly performed in a surgical ward of a hospital; also of two other patients, inmates of surgical wards, who had been exhibited to candidates at an examination for a diploma as examples of rbeumatoid artbritis. Charcot, in answer to a remark of this same authority, complaining of their rarity in England, said, "You will find them in the workhouse infirmaries, and in the surgical wards of hospitals." How true this remark was recorded cases testify.

In addition to the case I am about to record, in which, although the tabetic symptoms were recognised, a diagnosis of malignant disease was nearly completed and operative procedures almost resorted to, I can remember the case of a middle-aged man who came under my observation for incontinence of urine, at a time when I was house-physician to Dr. Gilbart Smith at the London Hospital, under whose care he was admitted. Here none of the ordinary causes of incontinence could be found, but the right hip-joint was much enlarged and disorganised by large irregular bony outgrowths, which also projected into the pelvis. The patient, a dull stupid man, had never before noticed the enlargement around the joint, but he walked lame with that foot. On inquiry into his history it was found that his lameness dated from an injury received some six or seven vears previously, in which he said his hip had been dislocated by its entanglement in a cart wheel. Further inquiries elicited the fact that he was the subject of marked ataxic symptoms; thus he had been subject for many years to sciatica, his pupils presented the Argyll-Robertson phenomenon, and there was a total absence of knee-jerk in both knees. He walked with the

Transactions, vol. i., p. 129

Ziemssen's Cyclopæedia of Medicine, vol. xiui., p. 126.

3 On the Eye Symptoms in Locomotor Ataxy, Ophthalmological Society's Transactions, vol. i. 4 On the Affection of Bones and Joints in Locomotor Ataxy, \&c.,
Brit. Med. Jour., March 5th, 1881. 